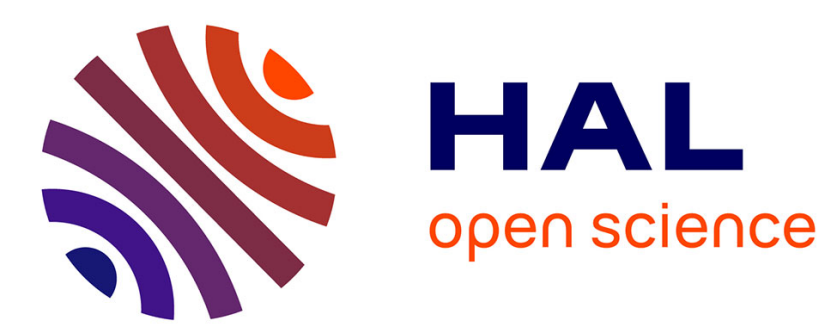

\title{
Hot pressing of nanocrystalline TiO2 (anatase) ceramics with controlled microstructure
}

\author{
Alicia Weibel, Renaud Bouchet, Renaud Denoyel, Philippe Knauth
}

\section{To cite this version:}

Alicia Weibel, Renaud Bouchet, Renaud Denoyel, Philippe Knauth. Hot pressing of nanocrystalline $\mathrm{TiO} 2$ (anatase) ceramics with controlled microstructure. Journal of the European Ceramic Society, 2007, vol. 27, pp. 2641-2646. 10.1016/j.jeurceramsoc.2006.11.073 . hal-00808352

\section{HAL Id: hal-00808352 \\ https://hal.science/hal-00808352}

Submitted on 5 Apr 2013

HAL is a multi-disciplinary open access archive for the deposit and dissemination of scientific research documents, whether they are published or not. The documents may come from teaching and research institutions in France or abroad, or from public or private research centers.
L'archive ouverte pluridisciplinaire HAL, est destinée au dépôt et à la diffusion de documents scientifiques de niveau recherche, publiés ou non, émanant des établissements d'enseignement et de recherche français ou étrangers, des laboratoires publics ou privés. 


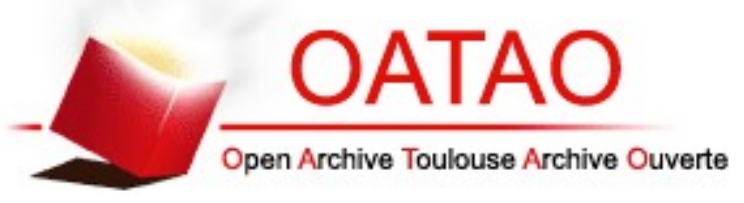

\section{Open Archive Toulouse Archive Ouverte (OATAO)}

OATAO is an open access repository that collects the work of Toulouse researchers and makes it freely available over the web where possible.

This is an author-deposited version published in: http://oatao.univ-toulouse.fr/ Eprints ID : 2475

To link to this article :

URL : http://dx.doi.org/10.1016/j.jeurceramsoc.2006.11.073

To cite this version : Weibel, Alicia and Bouchet, Renaud and Denoyel, R. and Knauth, Philippe ( 2007) Hot pressing of nanocrystalline TiO2 (anatase) ceramics with controlled microstructure. Journal of the European Ceramic Society, vol. 27 (nº 7). pp. 2641-2646. ISSN 0955-2219

Any correspondence concerning this service should be sent to the repository administrator: staff-oatao@inp-toulouse.fr 


\title{
Hot pressing of nanocrystalline $\mathrm{TiO}_{2}$ (anatase) ceramics with controlled microstructure
}

\author{
A. Weibel, R. Bouchet, R. Denoyel, P. Knauth* \\ MADIREL (UMR 6121), Université de Provence-CNRS, Centre St. Jérôme, 13397 Marseille Cedex 20, France
}

\begin{abstract}
The preparation conditions of nanocrystalline phase-pure $\mathrm{TiO}_{2}$ anatase ceramics by hot pressing are described. Density, surface area, pore size distribution and grain size are determined by various techniques, including gas adsorption, mercury porosimetry, transmission electron microscopy (TEM) and X-ray diffraction (XRD). The evolution of the structural parameters is followed as function of temperature and pressure programme. It is shown that the porosity, grain and pore size of the ceramics can be controlled by a suitable choice of experimental conditions. Ceramics with densities higher than $90 \%$ of the theoretical limit with a mean grain size of $30 \mathrm{~nm}$ can be obtained at temperatures as low as $490{ }^{\circ} \mathrm{C}$ under $0.45 \mathrm{GPa}$ for $2 \mathrm{~h}$. The experimental results are discussed in view of the sintering theory.
\end{abstract}

Keywords: Sintering; Grain size; Porosity; Oxides

\section{Introduction}

Materials with ultrafine grain size have attracted much interest by virtue of their unusual physical properties, very often with useful applications. A nanocrystalline ceramic is a dense material (relative density above $90 \%$ of theory) with a mean crystallite size below $100 \mathrm{~nm}$. Nanocrystalline ceramics exhibit ductility at low temperature, ${ }^{1,2}$ which is critical for the fabrication of ceramic components. In recent years, various studies on nanocrystalline binary oxide ceramics and thin-films have been published, including ceria, ${ }^{3,4}$ zirconia $^{5,6}$ and titania. A literature overview on sintering of nanocrystalline $\mathrm{TiO}_{2}$ reveals that dense rutile ${ }^{7-9}$ two-phase anatase-rutile ${ }^{10-12}$ or pure anatase nanoceramics ${ }^{13}$ were obtained. Various techniques were employed, including classical sintering, hot pressing and sinterforging. ${ }^{9}$ Siegel et al. ${ }^{14}$ determined by classical sintering that the densification of nanocrystalline $\mathrm{TiO}_{2}$ becomes significant at $500{ }^{\circ} \mathrm{C}$ and that grain growth starts at $550^{\circ} \mathrm{C}$, but remains slow until $800^{\circ} \mathrm{C}$. To avoid exaggerated grain growth, sintering must be performed at moderate temperature using pressure to accelerate the densification. Furthermore, it has been reported that

\footnotetext{
* Corresponding author. Tel.: +33 491637 114; fax: +33 491637111. E-mail address: knauth@up.univ-mrs.fr (P. Knauth).
}

grain growth becomes important when a relative density of $90 \%$ is achieved ${ }^{8}$ : grains can grow when the continuous network of pores breaks down on grain boundaries.

Hot pressing appears as a very appropriate technique to densify nanocrystalline ceramics. Hahn et al. ${ }^{7}$ reported an improvement of sintering with negligible grain growth by pressure application. However, a phase transition of anatase into rutile can occur at high pressure and temperature, in spite of possible stabilization of the anatase phase at small grain size. ${ }^{15}$ Temperature and pressure programmes applied to the ceramics must be optimized to keep the initial grain size and the original anatase phase. The objective of this work is to study the influence of experimental parameters of hot pressing, pressure $P$ and temperature $T$ on the grain and pore size of anatase ceramics. The microstructure of the ceramics is investigated by electron microscopy, the size of crystallites is determined by XRD and the pore size distribution is studied by nitrogen adsorption measurements and mercury porosimetry. Another objective is to interpret the evolution of these data in term of densification mechanism, including diffusion and plastic deformation contributions.

\section{Experimental}

The anatase powders were prepared by the sulfate route. ${ }^{16}$ In this process, the mineral precursor is dissolved in sulfuric 
Table 1

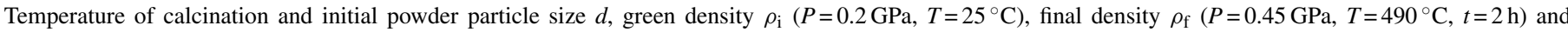
experimental conditions for a final density above $90 \%$

\begin{tabular}{|c|c|c|c|c|c|c|}
\hline \multirow[t]{2}{*}{$T_{\text {calcination }}\left({ }^{\circ} \mathrm{C}\right)$} & \multirow[t]{2}{*}{$d(\mathrm{~nm})$} & \multirow[t]{2}{*}{$\rho_{\mathrm{i}}(\%)$} & \multirow[t]{2}{*}{$\rho_{\mathrm{f}}(\%)$} & \multirow[t]{2}{*}{ Conditions for $\rho_{\mathrm{f}}>90 \%$} & \multicolumn{2}{|c|}{$d_{\text {ceramic }}(\mathrm{nm})$} \\
\hline & & & & & Scherrer & TEM \\
\hline 300 & $12 \pm 3$ & $45 \pm 5$ & $91 \pm 2$ & $490^{\circ} \mathrm{C}, 2 \mathrm{~h}$ & $50 \pm 20$ & $30 \pm 10$ \\
\hline 600 & $24 \pm 10$ & $51 \pm 4$ & $91 \pm 2$ & $490^{\circ} \mathrm{C}, 2 \mathrm{~h}$ & - & - \\
\hline 700 & $35 \pm 15$ & $54 \pm 4$ & $85 \pm 2$ & $680^{\circ} \mathrm{C}, 0 \mathrm{~h}$ & $60 \pm 20$ & - \\
\hline 800 & $70 \pm 35$ & $62 \pm 3$ & $78 \pm 2$ & $585^{\circ} \mathrm{C}, 2 \mathrm{~h}$ or $680^{\circ} \mathrm{C}, 0 \mathrm{~h}$ & - & $75 \pm 10$ \\
\hline
\end{tabular}

The given uncertainties are standard deviations from around 20 experiments.

acid and the titanium sulfate solution subsequently hydrolyzed by heating to $95-110^{\circ} \mathrm{C}$. The hydrolysis product is filtered and the filtrate thoroughly washed until neutral $\mathrm{pH}$ is obtained. It is then calcined under air for $1 \mathrm{~h}$ at different temperatures ranging between 300 and $800{ }^{\circ} \mathrm{C}$, which allow several powdered samples differing by their particle size distribution to be prepared. The list of samples is given in Table 1. The obtained powders were chemically analyzed by gravimetric techniques and ICP emission analysis ${ }^{17}$ : total impurity content is lower than $0.25 \mathrm{~mol} \%$ for all samples. The mean particle sizes were determined by three experimental methods that are in good agreement for this set of samples ${ }^{17}$ : X-ray diffraction (XRD, which gives access to the crystallite size), transmission electron microscopy (TEM) followed by image analysis on more than 100 particles and nitrogen adsorption measurements (a mean particle size is determined from the surface area by assuming spherical shape for the particles).

The hot press is a prototype built in collaboration with Cyberstar, Grenoble. ${ }^{16}$ It permits densifying the ceramics under uniaxial load of up to $5000 \mathrm{~kg}$ at temperatures up to $1100^{\circ} \mathrm{C}$. The dies are made from pure alumina with internal diameters of 4, 6, and $12.7 \mathrm{~mm}$ (SOTIMI, Grez sur Loing). The procedure is to apply first the pressure and then to increase the temperature with a rate of $5 \mathrm{~K} / \mathrm{min}$. After reaching the desired temperature, the sample is either directly cooled down or held at this plateau temperature for $2 \mathrm{~h}$ before cooling down. The real sample temperature was measured by a Pt-Rh30\%/Pt-Rh6\% thermocouple. Relative densities were calculated using the geometrical dimensions, the mass of the pellets and the theoretical density of the anatase phase: $3.84 \mathrm{~g} \mathrm{~cm}^{-3}{ }^{18}$

$\mathrm{X}$-ray diffraction was used to check the phase purity of the ceramic samples and to determine the mean crystallite size $d$ from Scherrer's equation:

$d=\frac{\lambda}{W \cos \theta}$

$W$ is the full width at half maximum of the (1 01$)$ and $(200)$ diffraction peaks of the anatase phase and $\theta$ is the Bragg angle. Instrumental line broadening is corrected as described previously. ${ }^{17}$ These tests were carried out on a Siemens D5000 diffractometer with conventional Bragg-Brentano $(\theta-2 \theta)$ geometry and $\mathrm{Cu} \mathrm{K} \alpha$ radiation $(\lambda=0.15406 \mathrm{~nm})$. Step size was $0.01^{\circ}$ with a counting time of $4 \mathrm{~s}$.

The ceramics microstructure was observed by high resolution Scanning Electron Microscopy with field emission gun (Philips
XL305) in secondary electron mode at $10-15 \mathrm{kV}$ acceleration voltage. Furthermore, thin ceramic samples prepared by Focused Ion Beam cutting (Philips FIB 200) were observed by Transmission Electron Microscopy (JEOL 2010 F, operated at $200 \mathrm{kV}$ ). Nitrogen adsorption and mercury porosimetry measurements were performed at $77 \mathrm{~K}$ and ambient temperature, respectively, using commercial apparatuses (Micromeritics ASAP 2010 and Autopore II 9220).

\section{Results and discussion}

\subsection{Evolution of relative density}

Detailed microstructural characterizations of powders, which present an agglomerated state, were described in a previous paper. ${ }^{17}$ The average particle sizes and standard deviations, determined by TEM observations, are summarized in Table 1 for powders calcined at $300,600,700$ and $800{ }^{\circ} \mathrm{C}$ for $1 \mathrm{~h}$. The green densities obtained by cold compaction at $0.2 \mathrm{GPa}$ of the powders (Table 1) show a particle size dependence. During cold compaction, a low densification occurs by partial de-agglomeration or by rearrangement due to sliding, which depends on granulometric characteristics of the initial powder. The increased green density may be due to better packing associated with small particles filling the voids between bigger ones, according to ref. ${ }^{19}$ This is why the green density increases with the relative width of the particle size distribution, which increases here with the particle size.

The isothermal density evolution as function of pressure (Fig. 1) at $490{ }^{\circ} \mathrm{C}$, for powders with initial particle sizes below $30 \mathrm{~nm}$, shows a plateau above $0.45 \mathrm{GPa}$ with densities around $90 \%$. The similarity of experimental data obtained with different internal die diameters shows that pressure repartition in the die is relatively homogeneous. This result was confirmed by other experiments with pellets of lower thickness. Between 0.1 and $0.4 \mathrm{GPa}$, the relative density evolution versus pressure can be expressed by a power law with exponent $1 / 4$ (Fig. 1)

$\rho_{\mathrm{f}} \approx K P^{1 / 4}+\rho_{\mathrm{i}}$

where $\rho_{\mathrm{i}}$ is the green density at $25^{\circ} \mathrm{C}$.

The isobaric density evolution as function of temperature was studied at a pressure of $0.45 \mathrm{GPa}$ (Fig. 2) for powders with initial particle sizes below $30 \mathrm{~nm}$. The flattening of the density curve observed beyond $500{ }^{\circ} \mathrm{C}$ corresponds to a relative density above $90 \%$, as reported before for the pressure dependence at $490^{\circ} \mathrm{C}$. 


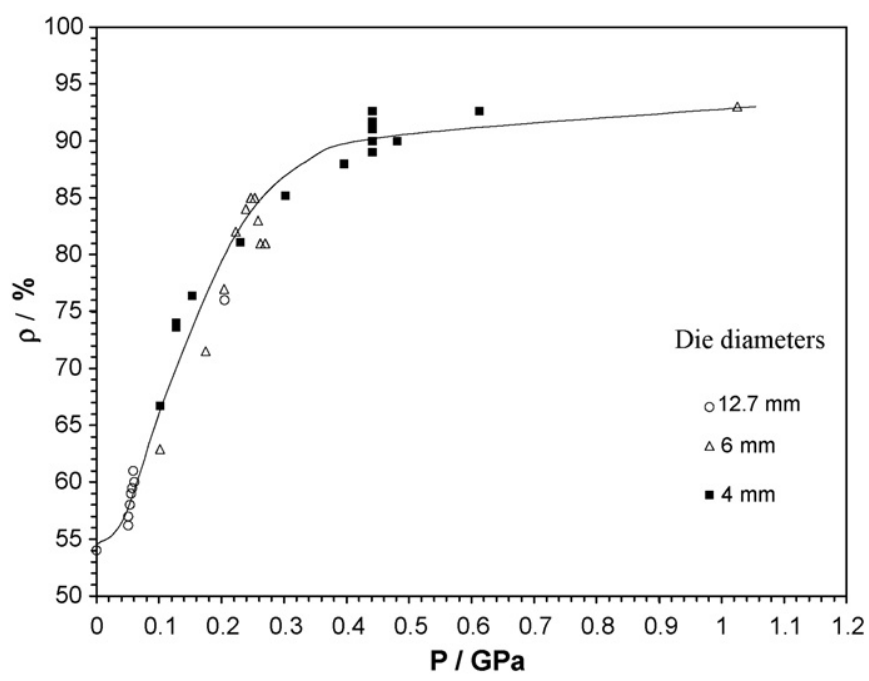

Fig. 1. Density evolution as function of pressure at $T=490{ }^{\circ} \mathrm{C}$ for $2 \mathrm{~h}$ $(d<30 \mathrm{~nm})$. A line is drawn through the experimental points to guide the eye.

Fig. 3 shows an Arrhenius plot with density data up to $490^{\circ} \mathrm{C}$. The corresponding effective activation energy is small, around $0.1 \mathrm{eV}$. The exponential temperature dependence observed in Fig. 2 confirms that the sintering is thermally activated, but the determined activation energy is very low, which is in agreement with a sintering mechanism by superplastic deformation, as reported previously for nanocrystalline materials, including $\mathrm{TiO}_{2} .{ }^{20}$

Favorable experimental conditions to synthesize dense nanoceramics appear to be $0.45 \mathrm{GPa}$ and $490^{\circ} \mathrm{C}$ with a temperature plateau time of $2 \mathrm{~h}$. Relative densities obtained with different mean powder particle sizes using the same experimental conditions are summarized in Table 1. One may notice that the relative density after sintering decreases with increasing powder size, whereas the opposite is observed for the green density (Table 1). Experimental conditions for obtaining a density above 90\% can also be found in Table 1.

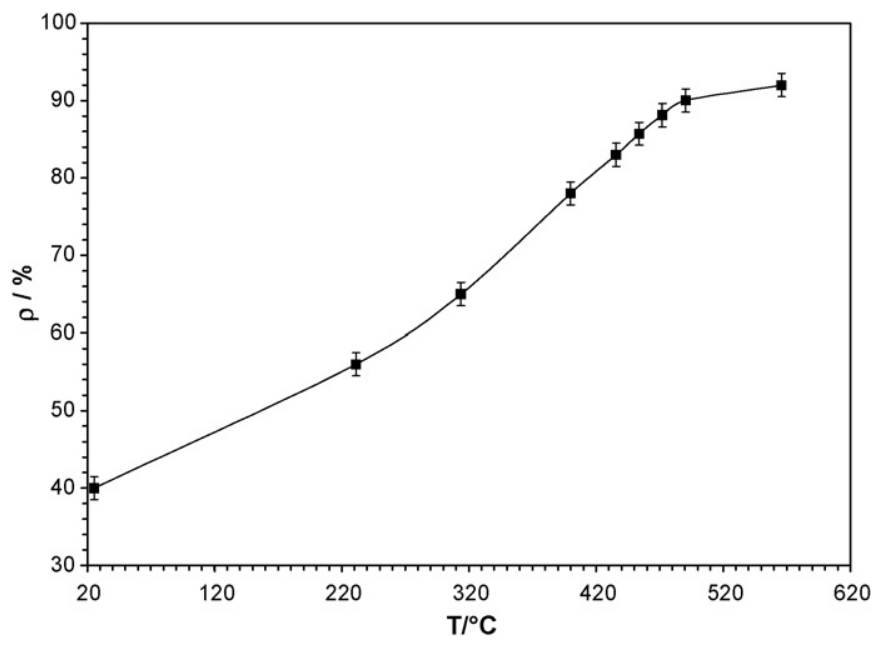

Fig. 2. Density evolution as function of temperature at $P=0.45 \mathrm{GPa}$ for $2 \mathrm{~h}$ $(d<30 \mathrm{~nm})$.

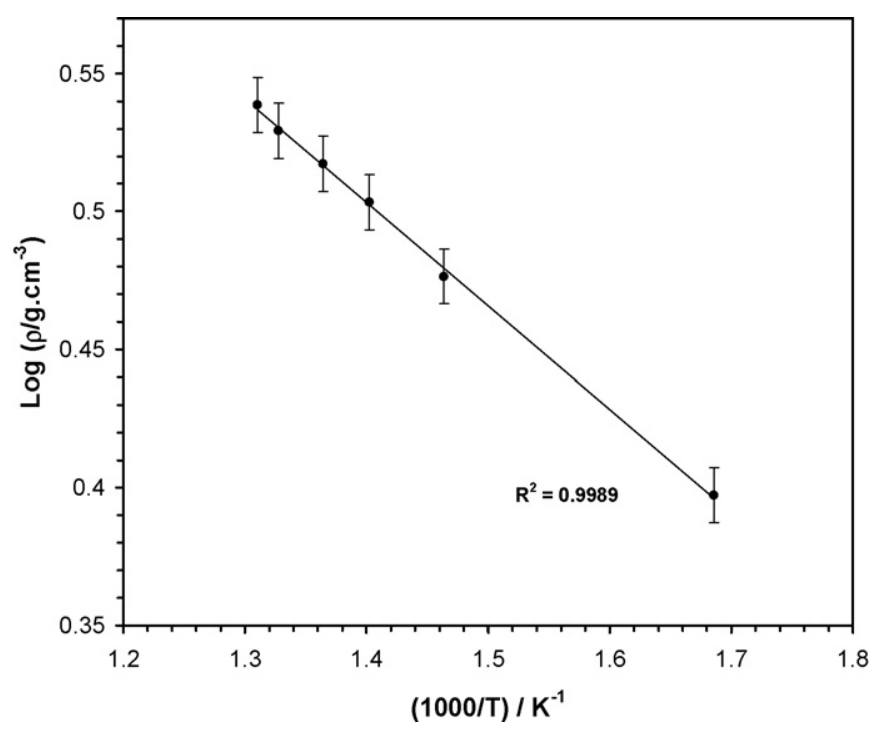

Fig. 3. Arrhenius plot of density values up to $490^{\circ} \mathrm{C}$.

\subsection{Structure and microstructure}

A phase transition of anatase into rutile is detected by XRD for the $70 \mathrm{~nm}$ powder sample densified at $680^{\circ} \mathrm{C}$ (Fig. 4d). Using the relative intensities of the most intense (10 1) peak of anatase and (1 110$)$ peak of rutile, a composition of approximately $5 \%$ rutile and $95 \%$ anatase can be estimated. Under the same sintering conditions, a dense and phase-pure anatase ceramic is obtained with the $35 \mathrm{~nm}$ powder sample (Fig. 4c). Inside the detection limit of XRD, the anatase phase appears destabilized for an average grain size around $70 \mathrm{~nm}$. Critical size values, corresponding to the beginning of phase transition into rutile, reported in literature vary between $10^{21}$ and $50 \mathrm{~nm} .{ }^{22}$ However, very small nuclei of rutile could be overlooked by X-ray diffraction. Furthermore, one can recognize by comparison of powder

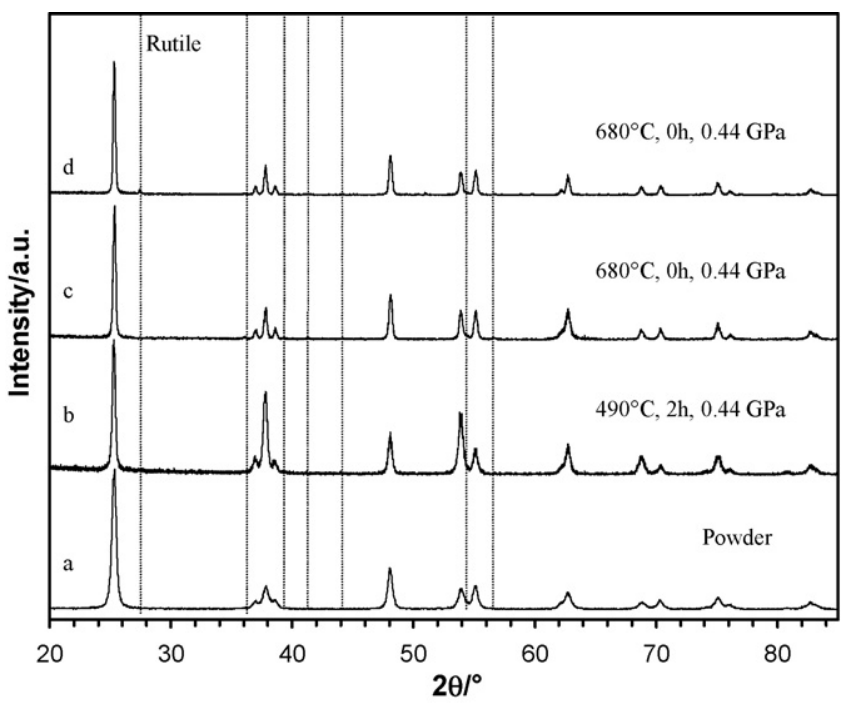

Fig. 4. X-ray diffraction patterns (a) powder with average particle size $35 \mathrm{~nm}$ and dense ceramics with average grain size (b) $30 \mathrm{~nm}$, (c) $60 \mathrm{~nm}$ and (d) $75 \mathrm{~nm}$. The dashed lines represent the most intense diffraction lines of the rutile phase. The $(004)$ and $(105)$ planes are observed at 38 and $54^{\circ}$, respectively. 


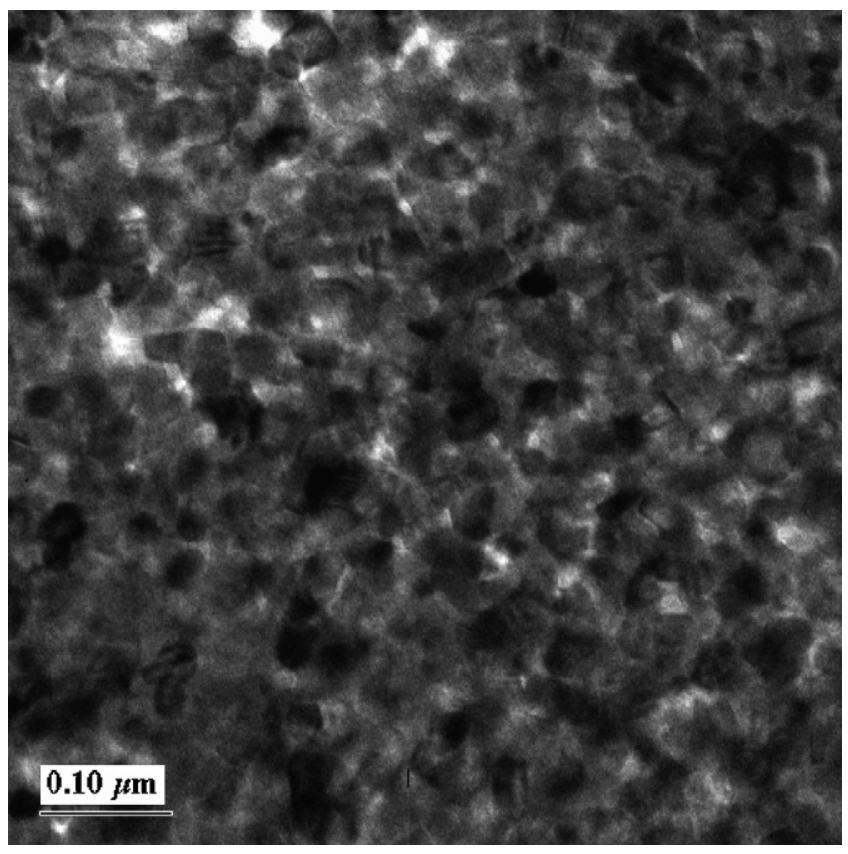

Fig. 5. TEM micrograph of a dense ceramic with average grain size $30 \mathrm{~nm}$.

(Fig. 4a) and ceramic pattern (Fig. 4b) preferred (004) and $(105)$ orientations, probably related to the pressure application on small particles during hot compaction. For larger particles (Fig. $4 \mathrm{c}$ and d), this orientation is not seen. The mean grain sizes from TEM observations of the ceramics are compared with values derived from Scherrer's equation (Table 1), assuming that the peak broadening is only due to crystalline domain size. In both determinations, the grain size is still in the nanometer range (i.e. $<100 \mathrm{~nm}$ ). Typical micrographs of ceramic samples are shown in Figs. 5 and 6. Fig. 5 is a TEM micrograph of a ceramic sample prepared from $12 \mathrm{~nm}$ powder according to the optimal conditions defined in Table 1. A SEM micrograph of a ceramic with $75 \mathrm{~nm}$ mean grain size prepared from $70 \mathrm{~nm}$ powder is represented in Fig. 6: only relatively little size change is observed by comparison with the initial powder, probably because the sintering temperature $\left(680^{\circ} \mathrm{C}\right)$ was below the calcination temperature of the powder $\left(800^{\circ} \mathrm{C}\right)$.

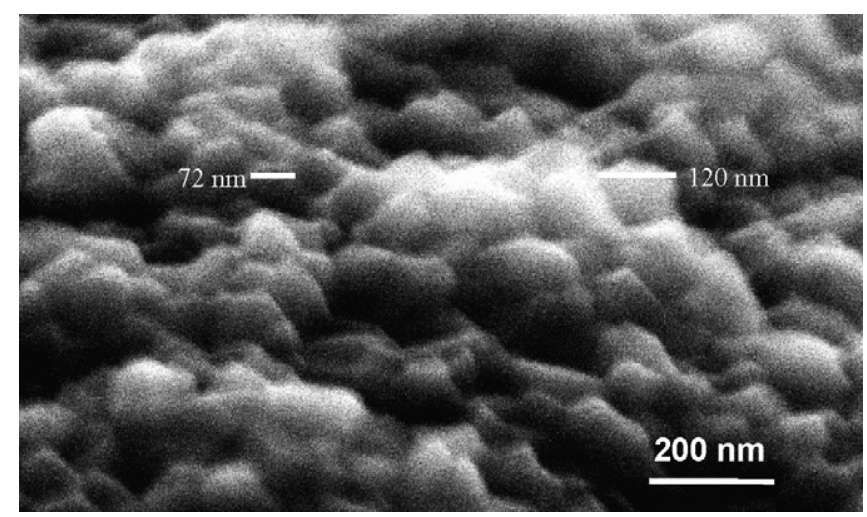

Fig. 6. SEM image of a dense ceramic with average grain size $75 \mathrm{~nm}$.

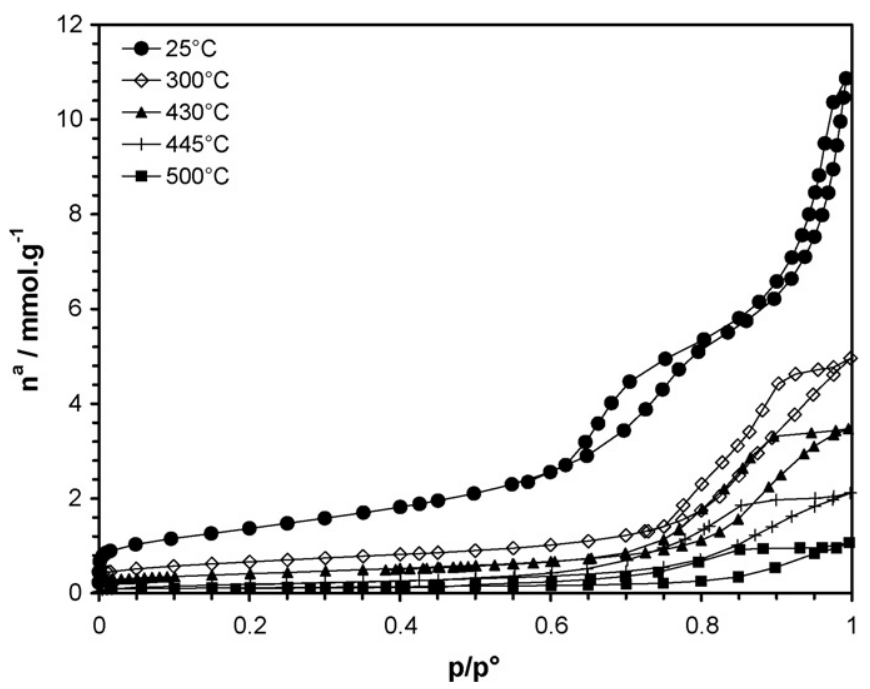

Fig. 7. Nitrogen adsorption isotherms of ceramics with different relative density.

\subsection{Surface area and pore size distribution}

The samples were characterized at different steps of the sintering process by gas adsorption and mercury porosimetry. For instance, a few adsorption isotherms of nitrogen at $77 \mathrm{~K}$ are presented in Fig. 7 for the ceramics based on $12 \mathrm{~nm}$ powder heated at increasing temperatures and constant pressure of $0.24 \mathrm{GPa}$. All the adsorption isotherms belong to type IV of the IUPAC classification, ${ }^{23}$ indicating that the samples are mesoporous. The adsorption isotherm of the sample obtained by cold compaction $\left(25^{\circ} \mathrm{C}\right.$ in Fig. 7) shows two well separated hysteresis loops (in the range $P / P^{\mathrm{o}}=0.6-085$ and above 0.9 ). This is related to the mesostructure of the powders than can be considered as the agglomeration of particles that are themselves made of the aggregation of small grains. The first hysteresis loops $\left(P / P^{\mathrm{o}}=0.6-0.85\right)$ corresponds to intra-aggregate pores, whereas the second one above $P / P^{\mathrm{o}}=0.9$ corresponds to inter-aggregate pores. During heating, the intra-aggregate pores first disappear as shown by the disappearance of the first hysteresis. At $300^{\circ} \mathrm{C}$, a step is still visible on the desorption branch in Fig. 7. It means that the two hysteresis loops merged in only one with temperature treatment. The first type of pores disappear, whereas the size of the largest decreases. From the application of the BET equation in the low pressure range (i.e. $P / P^{\mathrm{O}}<0.4$ ), it is possible to follow the evolution of the specific surface area of ceramics as shown in Fig. 8 for a ceramic sintered at $P=0.24 \mathrm{GPa}$ during $2 \mathrm{~h}$ at various temperatures. The important decrease of specific surface area for intermediate densities (45-65\%) can be directly related to the disappearance of the first hysteresis loop. To estimate the mesopore size distribution, the Barrett, Joyner and Halenda (BJH) model, ${ }^{24}$ based on capillary condensation in mesopores described by the Kelvin equation, was applied. The differential pore size distributions are reported in Fig. 9 for the same ceramic as in Fig. 8. This plot shows clearly a decrease of the mesopore volume (area under the curves decreases) and an important increase of the mean pore size for the first temperature step (between 25 and $300^{\circ} \mathrm{C}$ ) in agreement with the evolution of 


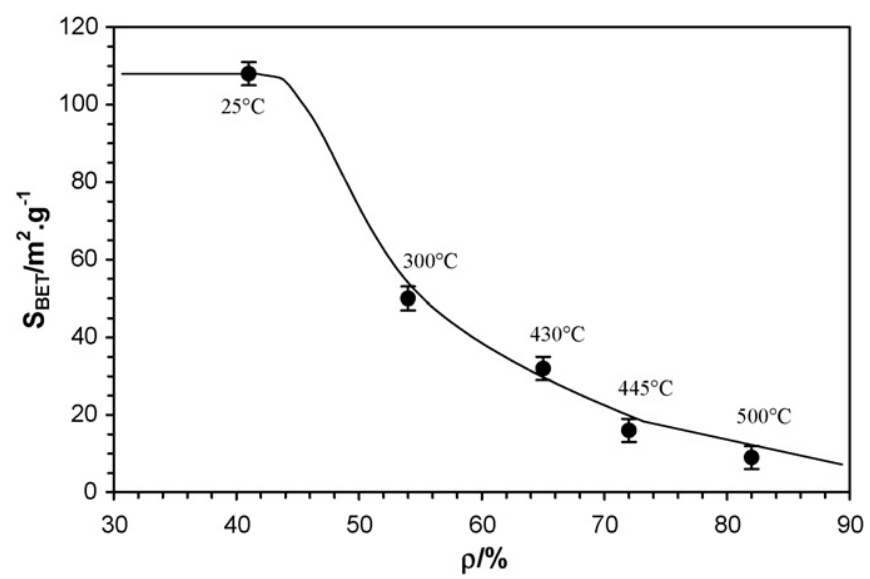

Fig. 8. Evolution of specific surface area of ceramics vs. relative density.

the hysteresis loops described above. An unexpected conclusion of these data is that the intra-aggregate pores disappear at a low temperature. Because the powder is already treated at $300^{\circ} \mathrm{C}$ before hot pressing, it is unlikely that this effect is due to crystal growth. Then the other possible interpretation is a superplastic deformation by crystal flow enhanced by the simultaneous application of temperature and pressure.

The evolution of samples sintered under various pressures at constant temperature $\left(490^{\circ} \mathrm{C}\right.$ for $2 \mathrm{~h}$ ) was followed by mercury porosimetry. Two peaks can be observed in the pore size distribution of the sample before heating $\left(0.2 \mathrm{GPa} T=25^{\circ} \mathrm{C}\right.$, in Fig. 10) in agreement with the results of gas adsorption (sample $25^{\circ} \mathrm{C}$ of Fig. 9). Quantitatively, the agreement with gas adsorption is good with a peak pore size around $8 \mathrm{~nm}$. The sample can be again described in term of aggregates that define two types of pores (inside and outside aggregates). After the first heating at $490^{\circ} \mathrm{C}$ until a pressure of $0.055 \mathrm{GPa}$, the sample is as strongly modified as the sample heated until $300^{\circ} \mathrm{C}$ at constant pressure: the volume of the smallest pores has strongly decreased, whereas the size of the largest pores is shifted towards lower values. Above $0.18 \mathrm{GPa}$, there is mainly one peak left on the pore size distribution. Table 2 shows a summary of surface areas, pore volumes and relative densities (from adsorption and sample geometry) at

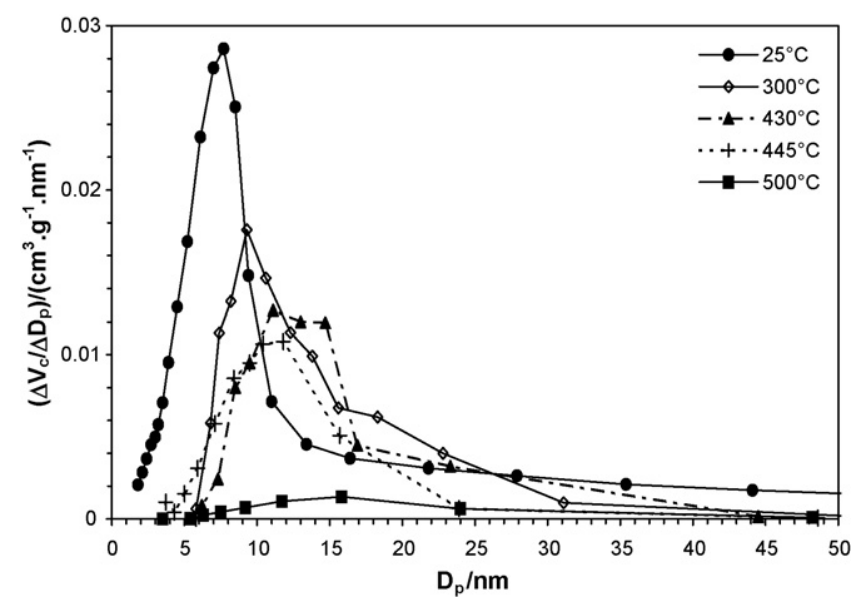

Fig. 9. Pore size distribution obtained from BJH model.

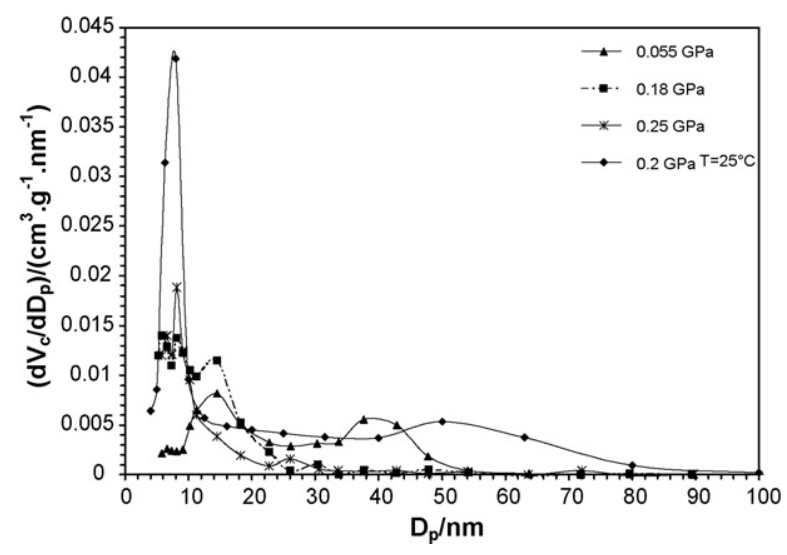

Fig. 10. Pore size distribution obtained from mercury porosimetry.

different sintering stages. There is globally a good agreement between the density values.

Temperature and pressure effects can be summarized as follows. At constant pressure, the population of small diameter pores decreases with temperature (Fig. 9) by diffusion processes. The apparent increase of average pore diameter is then attributable to the coalescence of grains inside agglomerates. In other words, the size of pores is proportional to that of grains. These results are in good agreement with sintering theory. ${ }^{25}$

The important decrease of specific surface area for intermediate densities (Fig. 8) is apparently higher than that calculated assuming a homogeneous pore distribution, which rises the important question of the homogeneity of the sintering process. For example, a BET specific surface area of $10 \mathrm{~m}^{2} \mathrm{~g}^{-1}$ is measured at $500{ }^{\circ} \mathrm{C}$, whereas calculation according to the equation valid for spheres

$S=\frac{6}{\rho d}$

where $\rho$ is the theoretical density of the anatase phase, ${ }^{18} d$ is the mean grain size of the ceramic, gives an area above $30 \mathrm{~m}^{2} \mathrm{~g}^{-1}$ if the grain sizes determined by TEM or XRD are used. The decrease of the surface area determined by adsorption could be caused by closing of pores at the pellet surface, i.e. there is a pore density gradient inside the pellets. This could prevent nitrogen gas from reaching pores inside the sample. Nevertheless, estimating the external surface area of the aggregates from the pore size distributions calculated by the BJH method (it corresponds to the surface of the pores evidenced by the second hysteresis loop in the case of the sample $25^{\circ} \mathrm{C}$ of Fig. 7) a value of $10 \mathrm{~m}^{2} \mathrm{~g}^{-1}$ is obtained, which is close to the surface area at

Table 2

Surface area $S$, pore volume $V_{\mathrm{p}}$, relative density $\rho_{\text {gas }}$ from gas adsorption measurements and relative density $\rho_{\text {geo }}$ from sample geometry

\begin{tabular}{rlll}
\hline$S\left(\mathrm{~m}^{2} \mathrm{~g}^{-1}\right)$ & $V_{\mathrm{p}}\left(\mathrm{cm}^{3}\right)$ & $\rho_{\text {gas }}(\%)$ & $\rho_{\text {geo }}(\%)$ \\
\hline 110 & 0.37 & 43 & 45 \\
50 & 0.17 & 63 & 56 \\
31 & 0.12 & 68 & 65 \\
15 & 0.07 & 79 & 72 \\
8 & 0.04 & 87 & 84 \\
\hline
\end{tabular}


$500^{\circ} \mathrm{C}$. Apparently the ceramic keeps a memory of the initial aggregates all along the sintering process. On the other side "grains" seen by XRD or TEM may correspond to crystallites that composed aggregates in which the porosity disappeared by superplastic deformation. Further densification relies then on diffusional processes only, which are slow at the reduced temperatures studied here.

\section{Conclusion}

The preparation of nanocrystalline $\mathrm{TiO}_{2}$ ceramics with controlled phase (anatase), grain and pore size and associated distribution was studied as function of the parameters temperature and pressure. Starting from powders that are composed of aggregates made of nanoparticles, it is shown that by simultaneous application of temperature and pressure the intra-aggregates pores are homogeneously eliminated at unusual low temperatures. On the other side, the elimination of inter-aggregate pores is not fully reached in the studied temperature range where the ceramics keep a memory of the initial aggregation state of the powder. These results confirm the importance of the initial state of the powder on the sintering process and open towards new approaches coupling powder processing to decrease aggregation and hot pressing to sinter at low temperature in order to keep a small grain size.

\section{Acknowledgments}

The authors thank Dr. A. Garnier (MADIREL) for the XRD measurements and Dr. W. Saikaly (CP2M) for help in the TEM investigations.

\section{References}

1. Betz, U. and Hahn, H., Ductility of nanocrystalline zirconia eased ceramics at low temperatures. Nanostruct. Mater., 1999, 12, 911-914.

2. Weertman, J. R. and Averback, R. S., Mechanical properties. In Nanomaterials: Synthesis, Properties and Applications, ed. A. S. Edelstein and R. C. Cammarata. Institute of Physics Publishing, Bristol, 1996, p. 323.

3. Chiang, Y. M., Lavik, E. B., Kosacki, I., Tuller, H. L. and Ying, J. Y., Defect and transport properties of nanocrystalline $\mathrm{CeO}_{2-x}$. Appl. Phys. Lett., 1996, 69, 185-187.

4. Kleinlogel, C. and Gauckler, L. J., Sintering and properties of nanosized ceria solid solutions. Solid State Ionics, 2000, 135, 567-573.

5. Hague, D. C. and Mayo, M. J., Modeling densification during sinter-forging of yttria-partially-stabilized zirconia. Mater. Sci. Eng. A, 1995, 204, 83-89.
6. Djurado, E., Boulc'h, F., Pivkina, A., Frolov, Y., Van Landschoot, N. and Schoonman, J., Cold isostatic and explosive isodynamic compaction of YTZP nanoparticles. Solid State Ionics, 2002, 154, 375-380.

7. Hahn, H., Logas, J. and Averback, R. S., Sintering characteristics of nanocrystalline $\mathrm{TiO}_{2}$. J. Mater. Res., 1990, 5, 609-614.

8. Averback, R. S., Höfler, H. J., Hahn, H. and Logas, J., Sintering and grain growth in nanocrystalline ceramics. Nanostruct. Mater., 1992, 1, 173-178.

9. Uchic, M., Höfler, H. J., Flick, W. J., Tao, R., Kurath, P. and Averback, R. S., Sinter-forging of nanophase $\mathrm{TiO}_{2}$. Scripta Metall. Mater., 1992, 26, 791-796.

10. Terwilliger, C. D. and Chiang, Y. M., Characterization of chemically- and physically-derived nanophase titanium dioxide. Nanostruct. Mater., 1993, 2, 37-45.

11. Kim, H. G. and Kim, K. T., Densification behavior of nanocrystalline titania powder compact under high temperature. Acta Mater., 1999, 47, 3561-3570.

12. Liao, S. C., Mayo, W. E. and Pae, K. D., Theory of high pressure low temperature sintering of bulk nanocrystalline $\mathrm{TiO}_{2}$. Acta Mater., 1997, 45, 4027-4040.

13. Knauth, P. and Tuller, H. L., Electrical and defect thermodynamic properties of nanocrystalline titanium dioxide. J. Appl. Phys., 1999, 85, 897-902.

14. Siegel, R. W., Ramasamy, S., Hahn, H., Zongquan, L., Ting, L. and Gronsky, R., Synthesis, characterization, and properties of nanophase $\mathrm{TiO}_{2}$. J. Mater Res., 1988, 3, 1367-1372.

15. Navrotsky, A., Energetic clues to pathways to biomineralization: precursors, clusters, and nanoparticles. PNAS, 2004, 101, 12096-12101.

16. Knauth, P., Bouchet, R., Schäf, O., Weibel, A. and Auer, G., Functionalized $\mathrm{TiO}_{2}$ nanoparticles for pigments, photoelectrochemistry, and solid state chemical sensors. In Synthesis, Functionalization and Surface Treatments of Nanoparticles, ed. M.-I. Baraton. American Science Publications, Stevenson, 2002 (Chapter 8).

17. Weibel, A., Bouchet, R., Boulc'h, F. and Knauth, P., The big problem of small particles: a comparison of methods for determination of particle size in nanocrystalline anatase powders. Chem. Mater., 2005, 17, 2378-2385.

18. Weast, R. C., ed., Handbook of Chemistry and Physics. 61st ed. CRC Press, Boca Raton, 1981.

19. Bernache-Assolant, D., Soustelle, M., Monty, C., Pastor, H. and Chaix, J. M., Chimie Physique du frittage. Hermes, Paris, 1993, p. 192.

20. Mayo, M. J., High and low temperature superplasticity in nanocrystalline materials. Nanostruct. Mater., 1997, 9, 717-726.

21. Zhang, H. Z. and Banfield, J. F., Understanding polymorphic phase transformation behavior during growth of nanocrystalline aggregates: insights from $\mathrm{TiO}_{2}$. J. Phys. Chem. B, 2000, 104, 3481-3487.

22. Hwu, Y., Yao, Y. D., Cheng, N. F., Tung, C. Y. and Lin, H. M., X-Ray absorption of nanocrystal $\mathrm{TiO}_{2}$. Nanostruct. Mater., 1997, 9, 355-358.

23. Sing, K. S. W., Everett, D. H., Haul, R. A. W., Moscou, L., Pierotti, R. A., Rouquerol, J. and Siemieniewska, T., Reporting physisorption data for gas solid systems with special reference to the determination of surface-area and porosity (recommendations 1984). Pure Appl. Chem., 1985, 57, 603-619.

24. Barrett, E. P., Joyner, L. G. and Halenda, P. H., The determination of pore volume and area distributions in porous substances.1. Computations from nitrogen isotherms. J. Am. Chem. Soc., 1951, 73, 373-380.

25. Kingery, W. D., Bowe, H. K. and Uhlmann, D. R., Introduction to Ceramics. John Wiley \& Sons, New York, 1976. 